\title{
Perceptions and Practices of Stimulating Children's Cognitive Development Among Moroccan Immigrant Mothers
}

\author{
Nabila el Moussaoui · Sjaak Braster
}

Published online: 21 September 2010

(c) The Author(s) 2010. This article is published with open access at Springerlink.com

\begin{abstract}
We explored the perceptions of children's cognitive development among Moroccan Arabic and Berber immigrant mothers who cannot read, who are less educated, middle educated or highly educated in the Netherlands. A series of in-depth interviews was conducted with 22 mothers with young children (mean age $=5$ years and 6 months). Qualitative data analyses revealed five major themes that are of significant importance to these mothers: moral attitudes, social values and religiousness; conversation, reading and playing as stimulating activities; importance attached to education; parental expectations; attributions of school success. The parental perceptions about the cognitive development of young children differed according to their own educational level. Mothers who cannot read and mothers with less education emphasized the development of moral, social and religious values for strengthening the cultural identity of their children. This sense of identity would enable them to function within their own cultural group and help them to perform well at school. School success was attributed in large part to a combination of the efforts of the child and the school. Middle and highly educated mothers, on the other hand, valued scholastic development and attributed school success to their own efforts and to the kind of support the child received. The ethnic background of the parents, whether Arabic or Berber, did not make a difference in the perceptions.
\end{abstract}

N. el Moussaoui $\cdot$ S. Braster $(\bowtie)$

Department of Sociology, Erasmus University Rotterdam,

P.O. Box 1738, 3000 DR Rotterdam, The Netherlands

e-mail: braster@fsw.eur.nl
Keywords Parental perceptions - Parental stimulation · Cognitive development · Moroccan immigrants . Parent-child interaction

\section{Introduction}

International research has continuously demonstrated that immigrant children perform relatively poorly in reading and arithmetic (OECD 2005). In recent decades much research has been done to explain or understand educational inequality with respect to the cultural and socioeconomic backgrounds of children (Blackledge and Hunt 1985). For a long time language deficiencies related to immigrant status or lower socio-economic background were key factors in explaining lack of educational success. Today researchers follow the path taken by Dewey, Piaget and Vygotsky (1978) and elaborate on the interaction between parents and children (Dockrell et al. 2004; Hart and Risley 2003; Leseman 2002). Academic success is best understood in the family context in which children grow up (Dockrell et al. 2004; Guo and Harris 2000; Hart and Risley 2003; Gottfried et al. 1998). Currently this context is understood not only in terms of socio-economic class, but also in terms of socio-cultural variables like ethnicity and levels of education (Leseman et al. 1995).

In order to understand the scholastic achievements of children with different socio-cultural backgrounds we must focus on the perceptions and beliefs of immigrants (Delgado and Ford 1998; Bornstein and Cote 2004). Not only are these beliefs important for the cognitive development of children, they also play a decisive role in the behavior of parents in this respect (Sigel and Kim 1996; Gauvain 1998). Moreover, these beliefs and values are transmitted to children through parental attitudes and 
practices (Sigel and Kim 1996) that facilitate the cognitive socialization of children (Gottfried et al. 1998). Thus, in order to understand socialization in migrant families, we have to understand the beliefs and perceptions that are part of the socio-cultural context in which socialization takes place (Delgado and Ford 1998; Gutman and McLoyd 2000; Bornstein and Cote 2004).

In early childhood, to a large extent, the home environment and parenting styles dominate the cognitive development of children (Bradley and Corwyn 2002; Menaghan and Parcel 1991; Landry et al. 2000; Raviv et al. 2004). Research demonstrated the intimate connection between parental beliefs and the academic achievement of children (Gutman and McLoyd 2000; Parks and Smeriglio 1986; Raviv et al. 2004; Van der Veen 2003; Walker et al. 1994). Linguistic development, as well as the development of reading and mathematics skills, depends on the sociocultural environment in which children are raised (Hart and Risley 2003; Raviv et al. 2004; Walker et al. 1994). The home can be seen as a learning environment that provides children with relevant informal learning opportunities (Dockrell et al. 2004; Hart and Risley 2003; Leseman et al. 1995). The learning opportunities that children get at home prepare them for the scholastic demands of primary education (De Jong and Leseman 2001; Okagaki and Sternberg 1993; Petril et al. 2004; Landry et al. 2000; Raviv et al. 2004). Differences in learning opportunities lead to important differences in knowledge and skills when children enter primary school (Hart and Risley 2003; Gutman and McLoyd 2000; Raviv et al. 2004; Leseman et al. 1995; Menaghan and Parcel 1991; Van der Veen 2003; Walker et al. 1994). The more children are challenged at an early age to develop their cognitive skills, the more successful their educational career at a later age will be (Hart and Risley 2003; Walker et al. 1994).

The informal learning environment that parents provide for their children depends on the complex interaction of socio-economic status, culture, ethnicity, and education (Bradley and Corwyn 2002; Okagaki and Sternberg 1993; Petril et al. 2004; Walker et al. 1994). The educational level of parents is an important variable with respect to the cognitive development of children. The higher the educational level, the better parents are able to contribute positively to the learning process of their children (Hart and Risley 2003; Van der Veen 2003; Walker et al. 1994). More highly educated mothers, for instance, use more varied and sophisticated language corresponding with the demands of primary education (Leseman 1990; Raviv et al. 2004; Walker et al. 1994; Hart and Risley 2003).

Although much research is done about the relation between the socio-economic status (SES) of families (traditionally measured with income, occupational status and educational level; Hauser1994) and the cognitive development of children within these families, little is still known about the complex interaction between these two concepts and the mechanisms that are involved (Bempechat et al. 1999; Bradley and Corwyn 2002). This applies especially to immigrants and ethnic groups. The relationship between SES components and developmental outcomes in immigrant groups is even more complex. How cultural perceptions of immigrants are related to and translated into parental practices is far from clear. In this respect many research findings contradict each other (Bradley and Corwyn 2002; Greenfield et al. 2003; Parks and Smeriglio 1986; Okagaki and French 1995). On the one hand, cultural beliefs are mentioned as the most influential factor in the cognitive development of children (Bornstein et al. 1991), while on the other hand, the importance of the educational level of parents is stressed (Hart and Risley 2003; Gutman and McLoyd 2000; Raviv et al. 2004; Van der Veen 2003; Walker et al. 1994).

First, on the basis of some research regarding the relation between cultural belief systems and the cognitive development of immigrant children, we know that there is a variation of cultural beliefs and values among several ethnic groups. At this time little research is being done to analyze the variation of those beliefs within a culturally homogeneous group. Secondly, we still know little about the influence of education or the new home environment on the cultural beliefs of immigrants. In addition to these two points, research in which perceptions of immigrants are studied in relation with the cognitive development of children uses constructs that are well known in a Western and middle class culture. This can be accepted from a sociological point of view because of its educational connection to the dominant culture (of primary education). However, from a cross-cultural view it is problematic because cultures differ in their conceptions about child development (Delgado and Ford 1998; Okagaki and Sternberg 1993; Bornstein et al. 1991) and therefore in their practices. Furthermore, some studies used standardized instruments to examine parental perceptions about child development. This strategy does not allow for an in-depth exploration of the cognitions and practices of parents with diverse cultural and ethnic backgrounds. An open and less restrictive approach would be more appropriate. It is primarily because of these limitations of present research that there is a gap in knowledge about the perceptions of Moroccan immigrants or environmental influences on cognitive development of Moroccan Dutch children in the Netherlands. The parents of these children, who came to the Netherlands from the 1960s onwards as labor migrants, are with 335.217 people $(2.2 \%$ of the Dutch population) the third largest ethnic group in the Netherlands (Central Bureau of Statistics 2009; Pels 2000).

Little is known about the perceptions and the kind of stimulating activities that Moroccan parents undertake to 
encourage the cognitive development of their children. What we know about these perceptions and activities is based on research from a Western and middle class perspective. How do Moroccan migrants look to cognitive development of young children and which activities do they undertake to stimulate cognitive development? What we need to do is to examine more closely the beliefs and the activities of Moroccan immigrants to gain insight about the informal learning environments they offer their children. Because of the significant influence of parental beliefs and goals on cognitive development in early childhood and because of the influence of this development on school success in later years, we consider a closer study into this matter relevant.

Our study, therefore, aims to qualitatively examine (1) the parental beliefs of Moroccan mothers in the Netherlands about the cognitive development of their children, and (2) the specific educational activities these mothers report that are provided at home to stimulate cognitive development. Secondly, we aim to explore the relationships between these perceptions and stimulating activities with (1) the educational level of the Moroccan mothers, and (2) their ethnic background: Arabic or Berber (Chafik 2004). In this study we focus on the beliefs of mothers because they function as the main caregivers.

\section{Method}

\section{Participants}

To explore the belief systems of Moroccan mothers about the cognitive development of young children, a total of 22 Berber and Arabic mothers (mean age $=34$ years, SD $=$ 3.88 , range $25-42$ years) participated in this study. The selection of these mothers was based on two criteria: their cultural identity, Arabic or Berber, and their social-cultural background, measured on the basis of the educational level that the mother has obtained in the Netherlands or the country of origin to the classification of the International Standard Classification of Education (ISED). The number of mothers with Arabic and Berber cultural backgrounds was the same: 11. The educational level was divided into four levels: mothers who could not read or write (no primary education), less educated mothers (only primary education; ISCED level 1), middle educated mothers (lower and upper secondary education, general or vocational; ISCED level 2, 3 and 4) and highly educated mothers (tertiary education: higher vocational education or university; ISCED level 5 and 6). Four mothers could not read or write, seven mothers were less educated, six mothers were middle educated and five mothers were highly educated. Table 1 provides a description of the mothers' educational level of two cultural backgrounds.
Table 1 Characteristics of the mothers: educational level by cultural background

\begin{tabular}{llllll}
\hline $\begin{array}{l}\text { Educational } \\
\text { levels }\end{array}$ & $\begin{array}{l}\text { No primary } \\
\text { education }\end{array}$ & $\begin{array}{l}\text { Primary } \\
\text { education }\end{array}$ & $\begin{array}{l}\text { Secondary } \\
\text { education }\end{array}$ & $\begin{array}{l}\text { Tertiary } \\
\text { education }\end{array}$ & Total \\
\hline Arabic & 2 & 5 & 1 & 3 & 11 \\
Berber & 2 & 2 & 5 & 2 & 11 \\
Total & 4 & 7 & 6 & 5 & 22 \\
\hline
\end{tabular}

Table 2 Characteristics of the children: gender by cultural background

\begin{tabular}{lccc}
\hline & Girls & Boys & Total \\
\hline Arabic & 7 & 4 & 11 \\
Berber & 3 & 8 & 11 \\
Total & 10 & 12 & 22 \\
\hline
\end{tabular}

Most families had two or three children (mean $=2.9$ children, $\mathrm{SD}=0.96$, range $1-5$ children). The research was focused on the child that was enrolled in the first, the second or the third grade of a primary school (mean age $=5.06, \mathrm{SD}=0.71$, range $4-6$ years). These children, 12 boys and 10 girls, should not have repeated a class. Table 2 provides a description of the gender of the children by cultural background.

The selection of the mothers was based on the information that was given by the primary schools that their children were attending. Two public primary schools were selected: one situated in a metropolitan city, the other in a village. The mothers were equally divided between the two schools. The participants were contacted at the school of the child by a letter, written in Dutch. In this letter we asked for voluntary participation and stated the purpose of the study. Parents that could not understand the Dutch language were asked personally to participate in their mother tongue. Other Moroccan parents of the two schools were providing their names. Half of the participants were selected in this way. The purpose and final result of this theoretical sampling procedure was an equal division with respect to the ethnicity of the mothers, the educational level of the families, the urban and local context of the school, and the gender of the children.

\section{Data Collection}

A set of interview questions was developed to explore their views on cognitive development. The interview questions were based on a review of 27 cross-cultural socialization literature (e.g., Blackledge and Hunt 1985; Decoviç and Gerris 1992; Bradley and Corwyn 2002; de Jong and Leseman 2001; Englund et al. 2004; Goodnow 1998; 
Greenfield et al. 2003; Hatano and Wertsch 2001; Landry et al. 2003; LeVine et al. 1996; Ogbu 1978; Okagaki and French 1998). Relevant aspects of cognitive development and stimulating practices were discussed, divided into various topics, and formulated in open-ended questions. The topics covered were the beliefs about cognitive development of young children, the mothers' role in this development, the kind of stimulating activities mothers were engaged in (including the importance of conversation, reading, play and language), the attributions of school success, and the parental beliefs about the importance of education and their educational expectations.

\section{Procedure}

In order to explore mothers' perceptions about cognitive development we used a set of open-ended questions. The interviewer first asked general questions about mothers' perceptions of scholastic learning. Mothers were asked: "What do you think are the most important issues for your child to learn at school?" Mothers were then asked specific questions like: "Are there things you are doing now at home to help your child to learn these things?" In order to gain more insight into the role mothers ascribe to school with respect to the cognitive development of their children, mothers were then asked: "Do you think the school should interfer to help your child learning those things?" and "What do you think the school should do to help your child to learn those things?"

Regarding stimulating activities and scholastic skills for which mothers prepare their children, questions such as these were asked: "What kind of activities do you do at home with your child?" and "What kind of skills do you think are important for your child to develop at school?" Mothers were then asked: "Are there activities you are doing now to stimulate the development of these skills?" After that, mothers discussed which skills were believed to be of importance for the cognitive development of their children and the kind of activities they undertake to stimulate the scholastic development.

In order to explore other activities which could be of importance for the cognitive development of children, the researchers also asked about the extracurricular activities of the child and the kind of activities families were undertaking with the child in their free time.

Regarding the educational aspirations of mothers, the following questions were submitted: "What do you think is the main reason for being successful in school?" and "What do you think is the most important goal for your child to achieve in school?" To find out what role the school should play in their educational aspirations, mothers were asked: "Do you think the school should interfere to help your child to achieve these goals?" and "What do you think the school should do to help your child to achieve these goals?" In their answers mothers elaborated on the reasons that were important for being successful at school and they spoke about their contributions for achieving this success.

All interviews were recorded on tape and directly transcribed. Each interview lasted about 2 or $2.5 \mathrm{~h}$. They were conducted in the school year 2006. More than half of the interviews took place in the mothers' homes. Ten were held in the school of the child. Neither during the interviews, nor at any other moment, were systematic observations made with respect to the way the mothers were interacting with their children. All mothers could choose the language they preferred to speak. About half of the interviews were conducted in Berber or Arabic. In the other half, Dutch was spoken. The first author who could speak Berber, Arabic and Dutch did all interviews and was trained in interview techniques. A set of pilot interviews was conducted and discussed with the second author before interviewing the mothers of the study sample.

\section{Data Analysis}

The transcribed interviews were coded using the qualitative methodology described by Strauss and Corbin (1990). In this approach, codes were developed through knowledge of previous theory and research. The first author organized the interview data in accordance with the topics mentioned above that were based on a review of the literature. Modifications or concerns were discussed with the second author. This process of data analysis resulted, after additional remarks made by two anonymous reviewers, in eight main categories. These categories were: (1) parents' views and values related to scholastic learning, (2) cognitive learning linked to maturity, (3) the concept of play and its significance to cognitive development, (4) conversation as a stimulating activity relevant to cognitive development, (5) reading as a stimulating activity relevant to cognitive development, (6) stimulating cultural and religious identity, (7) the attributions of school success, and (8) the importance of education and expectations. In a second step, both authors divided the interview data within a specific category into subcategories. In the case of categories with respect to stimulating activities like play, conversation and reading, this was done using two subcategories that indicated the importance of these activities for the cognitive development of children. In the case of the category of parents' views and values related to scholastic learning, for instance, two other subcategories were made: one that stressed the importance of social and moral development, and another that stressed the importance of intellectual encouragement. Again, both authors discussed this dimensionalization of the categories, and-independently of each 
other-coded the interview fragments in terms of the importance that parents were giving to a specific category. In more than 80 percent of the cases the authors agreed with each other. In the others cases, the disagreement was only about the degree of importance that was assigned to a category. In all these cases the differences were small: they could be resolved between the coders after minor discussions. In the end, the coders were able to divide all answers of the mothers to the several questions into two subcategories for each of the eight main categories that were theoretically chosen on the basis of the research literature. The coding process did not result in the addition of new main categories. In a third step, the coding of parental perceptions and practices in categories and subcategories was related to the ethnicity of the mothers, the educational level of the families, the urban and local context of the school, and the gender of the children. In this article we will focus on education and ethnicity. The results are presented in the following paragraph, including examples of interview fragments that were relevant for a specific subcategory.

\section{Results}

\section{Mothers' Views and Values Related to Scholastic Learning}

Arabic and Berber mothers, who cannot read and who are less educated, place scholastic learning in the context of social-moral development with an emphasis on the transfer of cultural and moral values. Ten mothers say they believe in the importance of transmitting moral values at a young age. The values that are reported to be important are respecting elderly people, obedience to parents and elderly family members, good manners, and knowing the difference between good and bad.

Interviewer: "What do you think are the most important issues for your child to learn at school?"

Parent: "Well, I think children can learn a lot. The rights of their parents, the meaning of love, love of brothers and sisters. Family members. The rights of neighbors, how to interact with them. Respect, how to treat people respectfully. Well, treating others with decency. They learn how to behave themselves, respectable and wellmannered. How to address elderly people, you know respectful. If you don't teach them these things, than they grow up that way, not knowing what respect is and not able to address people in a decent way. They have to know to treat their parents respectfully and that they got to listen to them" (Berber, less educated).

Interviewer: "What do you think are the most important issues for your child to learn at school?"
Parent: "I think parenting has a great influence on the development of children. As a parent you have a contribution in this happening. If you don't do anything, I am afraid they will learn bad things from the outside, or good things, you never know for sure. But I think they will learn bad things, because at home they don't learn what's good and bad. If they don't learn at home what's good and wrong, they will not learn this on the street. When they become older, you won't be able to teach them that, so you have to do it when they are sensitive to this, when they are young" (Arab, less educated).

The developmental stage that is characterized as sensitive and influential is said to be the age between 3 and 6 years old. At this stage children develop moral consciousness, according to the mothers. The socialization factors, which the mothers promote, are reported to be assimilated much faster at this stage. On the question of which skills are thought to be relevant for scholastic learning, mothers who cannot read and mothers with less education emphasize issues with respect to social and moral development. The statements of middle and highly educated mothers point towards a different conceptualization. These mothers place learning in the context of scholastic achievements and stress the intellectual encouragement at a young age for an optimal transition at school.

Interviewer: "What skills do you think are important for your child to develop at school?"

Parent: "As a parent I'm convinced of the fact you can contribute to the intelligence of your child. Reading from a good book, interacting about that to expand their intellect is a start, involving your child in a lot of interactions and answering their questions, helps constructing knowledge." It makes a remarkable difference when they enter the primary school, it makes the transfer to school much easier" (Berber, highly educated).

Interviewer: "I see, and are there things you are doing now to encourage X?"

Parent: "Before his birth I read books for X. I'm still reading books for him, I tell stories and sing to him. Although he doesn't understand everything, by offering this as soon as possible, he learns a lot. It's wonderful to see how this affects his development" (Arab, highly educated).

\section{Cognitive Learning Linked to Maturity}

When asked about learning of basic concepts like colors, spaces, figures, and new words, eight mothers, who cannot read and less educated mothers state that they believe that children at a young age are not able to learn school related skills. These mothers say that young children are not able 
to exert cognitive efforts. They report that they are not worried about the development of scholastic skills and the Dutch language because children acquire these skills in a natural way as they become more mature. Berber and Arabic mothers who cannot read and less educated mothers tend to identify learning, to a large extent, as a natural process that does not need any guidance or intervention from parents. In their conversations with the interviewer, a mother who cannot read and a less educated mother explained their point of view as follows:

Interviewer: "And what things you are doing now at home to encourage the development of X?"

Parent: "I think school is an important place to learn a lot of things. I trust learning those school things at school. Right now $\mathrm{X}$ is too young to learn that, but when she is older, she will be able to learn that at school" (Arab, mother who cannot read).

Parent: "Right now I don't read books to X, she is too young for that. She can't read yet."

Interviewer: "Okay, are there other activities you do to prepare X for school issues?"

Parent: "Well, as I said before, she is far too young to learn those school things. It will come easily when she becomes older. I will help her then." (Berber, less educated).

Interviewer: "What do you mean "not waiting with stimulating activities"?

Parent: "Well, he will get that matter at school, but when you help the child, learning will be easier when the child starts at school. I think the second step of learning will be easier. So, he (child) will learn those things at school. You can teach him those school things now, but it doesn't have any meaning. He is just too young. He doesn't understand yet. But when they begin learning in the third class, than you can definitely teach them something, they are older then" (Arab, less educated).

The crux of these ideas seems to lie in the connection between age and maturity. The older the child, the more mature the child will be to develop cognitively. Mothers state that this development can start around the age of 6-7. This perception appeared to be related closely with the school curriculum and the way in which subjects for learning are presented to young children. Mothers, therefore, believe that 4 and 5 year-olds cannot learn academic skills. One of the reasons most mentioned is the amount of playing that is done in the first two grades of primary school. According to the mothers, children do not learn in these first years at school. They mainly play which is not seen as learning.

The process of learning involves reading, writing and counting. The mothers don't speak about the preparation for these skills at an early age. They state that the ability to learn cognitive skills will develop without any preparation in the early school years or at home. Being able to master cognitive skills is seen as a matter of maturity. This parental perception seems to be reinforced by the Dutch school system. Reading skills are not specifically taught until the third grade. This empirical fact constitutes one of the essential reasons for not valuing informal learning or playing as a stimulus for cognitive development.

Middle and highly educated mothers tend not to establish a clear line between age and skills. Although maturity is mentioned as an important component in the development of children, stimulating cognitive skills before going to school is, according to them, relevant.

Interviewer: "Are there other things you are doing now at home with X?"

Parent: "I read her lots of fairytales. I sing with her. We read stories, we sing rhymes. She (child) likes very much to do all these things. It's good for her, she learns a lot of words and it improves her language development. Only by undertaking a lot of activities she learns this kind of things. She also watches cartoons for her Dutch. She hears and learns new words" (Berber, middle educated). Interviewer: "I see, and are there other things you are doing at home with X?"

Parent: "Because $\mathrm{X}$ is with me in the kitchen, doing lots of things, he learns a lot of words and terms. But also figures and the amounts they express. Especially the amount a figure expresses, that's very important. He learns that by helping me in the kitchen, very naturally, by playing" (Arab, highly educated).

The Concept of Play and its Significance to Cognitive Development

According to mothers who cannot read and less educated mothers, playing does not involve cognitive actions: with play as an activity no knowledge is constructed. Play is mentioned as an activity where a child amuses himself. These mothers report that young children do not learn essential subjects in the first 2 years of the primary school, because of the amount of play in the first 2 years of Dutch primary education.

Interviewer: "Okay, could you explain to me why you think it's senseless to prepare $\mathrm{X}$ on school issues like reading as you mentioned before?"

Parent: "Well, look they don't yet learn anything at the first 2 years of kindergarten. The first 2 years consists only of playing. I don't think it's important at that time to provide help. She only plays" (Arab, less educated). Interviewer: "What do you mean, "she doesn't learns a lot"? 
Parent: " $\mathrm{X}$ is too young, she's in the second class, now she plays a lot there, she doesn't do many things, it's all playing with dolls, puzzles and things like that. She is too young to learn school things right now. She will learn this next year if she moves to the other class. She will learn there a lot of things, now she is too young for that. Now she's just playing" (Arab, mother who cannot read).

As to the question of whether mothers themselves play with their children, seven mothers gave a negative response. Three mothers with less education report experiencing stress after working in the house and, therefore, do not have the energy to play with their child. If these mothers do play with their children, then it is framed in the context of recreation, amusement, and showing affection.

Interviewer: "And do you play with X?"

Parent: "I would like to do more things with my child if I had more spare time. I'm just too tired for those things. I just don't have the energy after my work" (Berber, less educated).

Middle and highly educated mothers tend to look at play as an activity for their children to acquire knowledge about the world. Therefore, they report that they play a lot and do various activities such as visiting the Zoo, amusement parks or museums. All mothers report having many kinds of toys at home, including a computer that is mainly used for playing games. Highly educated mothers mention explicitly games to stimulate learning like reading and counting skills. Mothers who cannot read and less educated mothers report that they rely on the teacher for the development of cognitive skills.

Interviewer: "And why do you think it's important to play with $\mathrm{X}$ ?"

Parent: "Children learn a language between 0 and 2 years. This is a sensitive period and the best period at which children acquire a language. That's why I read a lot to my children and play a lot with them, so that they can learn to distinguish different tones" (Berber, middle educated).

Parent: "Well, children learn a lot by playing. I play memory games with cards with $\mathrm{X}$, that is to help him to learn figures and the amounts they express. He also learns to memorize. He likes very much to turn the cards and to remember the figures he saw. Well things like this, they learn a lot just by playing" (Arab, highly educated).

\section{Conversation as a Stimulating Activity Relevant to Cognitive Development}

All mothers who cannot read and two mothers with less education mention conversation as one of the most important stimulating activities. This group of mothers reported talking a lot with their children, especially to stress the importance of social and moral values. One of these values is to listen to the teacher and to behave properly at school. Furthermore, children listen and participate in conversations about value related issues at home. Talking about the right values is considered to be an important way to teach these values. Visiting family members are also mentioned as a means to develop proper social values.

Interviewer: "I see, $\mathrm{X}$ doesn't understand everything. What do you think $\mathrm{X}$ understands about the things you are talking about?"

Parent: "Well, there are lots of things which I can't talk about. I think he is far too young to understand such things. Things like space, animals. He asks me why parents divorce, questions about the existence of God, that kind of questions. Those kinds of things are too difficult for him to understand. I don't talk about that. I do talk about things that he can understand, things like shame, or how to behave when there are visitors. You have to tell them, otherwise they will not know what appropriate behavior is" (Arab, less educated). Interviewer: What do you mean "talking is better"? Parent: "Look, talking is much better than punishing because you explain why you are not allowed to do certain things. It's very good to talk and to explain what's bad and not. It also helps to reward children. I talk a lot to $\mathrm{X}$ about God and what we are allowed to do or not, telling lies for example. If you explain things, they understand much better why things are the way they are. They remember the next time" (Arab, less educated).

Mothers who cannot read and mothers with less education report talking about moral and social issues. In addition to this, middle and highly educated mothers also mention the transfer of knowledge and the need to stimulate a child to ask questions. Two mothers put it this way:

Interviewer: "You said you think talking is important, could you explain to me what mean?"

Parent: "A lot of talking is very important for children because they learn a lot of things. Due to talking, children learn and gain a lot of information about the world. If you offer them information, that raises a lot of questions, then you can talk about those things by answering their questions" (Arab, highly educated).

Parent: "I talk a lot with X."

Interviewer: "Do you want to give me some examples about the things you talk about?"

Parent: "We talk about things we come across while walking to school. I point out things we see and I tell him 
some things about them. Or he (child) asks me questions about things and I explain to him about them. Last time he asked me why leaves change color and fall during autumn. Of course he doesn't understand everything, but he does understand a lot" (Berber, middle educated).

Reading as a Stimulating Activity Relevant to Cognitive Development

All mothers recognize the importance of reading for the academic development of their children. The reasons, that are mentioned, concern extending the knowledge about the world, extending the vocabulary of the Dutch language, stimulating the child to read for himself, and preparing the child for the reading process that starts at the third grade of Dutch primary schools.

Interviewer: "Could you explain why you think reading is good?"

Parent: "I think it's good for their development."

Interviewer: "What kind of development do you mean?"

Parent: "Well, I think they get smarter when you read them a story. I don't know, I read that in a magazine. She (child) likes that very much, during reading she points to illustrations, she tries to understand, and I think that's good to learn to read" (Arab, less educated).

Interviewer: "You said you think reading is important, why do you think so?"

Parent: "I think reading is one of the most important things to do. I think it's very informative for children, even though they can't read. You can read to them, it's important for them to hear stories. By reading books, they can develop knowledge about different subjects. Children ask a lot of questions, as a parent you can count on that" (Berber, middle educated).

Interviewer: "What activities do you do With $\mathrm{X}$ at home?"

Parent: "I do a lot of things with X. I read Classic Arabic stories to him so that he learns sophisticated language. I recite rhymes, we sing. I started this when he was a couple of months old. When he was two I started reading short stories, while looking together at pictures to learn colors and shapes, things like that. Well, I have different kind of books for teaching colors and characters for reading. That's quite important for school and for his intellectual development" (Arab, highly educated).

Although all mothers who cannot read and four of less educated mothers never read to their children, they do realize and recognize the importance of reading. They use the same arguments as highly educated mothers. Mothers who cannot read make up for their lack of reading to the child by asking their spouses or the older brothers and sisters, if possible, to perform this task. For the development of the Dutch language they say they rely on television programs, especially cartoons.

Interviewer: "So do you read to X?"

Parent: "Well, I can't read Dutch, so I ask my husband to read to X. Sometimes I also ask $\mathrm{Y}$ to read to his brother" (Berber, mother who cannot read).

An interesting observation can be made with respect to the beliefs of mothers who cannot read and less educated mothers. On the one hand, they reported that they appreciate preparation for reading. This preparation is valued because it familiarizes children with the Dutch language. It actually offers some kind of academic support and it is thought to be of great importance for the reading skills and the comprehension of the Dutch language in the third grade. They all endorse the importance of preparation for reading and say that it has a great influence on the learning process. On the other hand, the same mothers say they don't believe in the ability of children from 4 to 6 years old to learn academic skills. For this reason they think it is not necessary to encourage cognitive development. Despite the fact that these mothers adhere to this idea, they do recognize and appreciate preparation for necessary school skills. While mothers point out the difference that acquired knowledge can make in the efforts of the child, they also admit that it cannot contribute to their children's cognitive development as a consequence of their perceived lack of education.

All mothers who cannot read and less educated mothers also admit that playing has an influential role in the learning process. These mothers, however, ascribe the development of scholastic skills to school and the development of social values to home. An Arab mother who cannot read explained to the interviewer:

Parent: "Learning is something for school. I trust on the teachers to do their job. Of course I would like to help at home, but I can't teach her how to read, write or counting skills. They (children) learn such things at school, so they must learn this at school."

\section{Stimulating Cultural and Religious Identity}

Mothers who cannot read and mothers with less education stress two issues with respect to the socialization of their children. The first issue concerns mastering their native language and is considered to be of great importance for the development of their cultural identity. The second issue regards the value of religion.

Seven of eleven mothers who cannot read and less educated mothers report speaking their native language with their children (Arabic or Berber). These mothers 
report that they worry about the disappearance of their native language if they do not stimulate children to speak in their native language at home. Mastering their native language is also considered important for communicating with other family members in the country of origin. Children are encouraged to accompany their mothers when they visit members of the family in order to learn to communicate in Arabic or Berber and to foster positive family relationships. Watching TV and listening to music in their native language is also mentioned. At the age of six, children can attend Sunday school where they learn to speak and write the Arabic language.

Interviewer: "In which language do you communicate with X?"

Parent: "I speak my native language with my child. That's very important for his background and religion. He has to know his roots, his religion, that's very important. He must not forget his identity. That's the responsibility of the parents. They have to speak their native language in order to teach that to their children. Otherwise they will forget" (Arab, mother who cannot read).

Interviewer: "Do you speak Arab all the time with X?" Parent: "Not all the time, most of the time. When they learn Dutch, they speak Dutch at home."

Interviewer: "What do you hope your child to achieve at the Sunday school?"

Parent: "I hope she will learn to read and write to become able to read the holy book. She will also learn the Arabic language. Finally I hope she will learn how to pray. It's very important not to forget the language of her parents and grandparents. It's her native language, her roots. It's important to be able to communicate with others. But above all for religion" (Arab, mother who cannot read).

Mothers who cannot read and less educated mothers say that they realize that a limited proficiency in Dutch language can have a negative effect on success in school. They report giving priority to the promotion of their native language, and delegate the responsibility for teaching the Dutch language to schools. Furthermore, these mothers report that due to their limited proficiency in Dutch, they do not want to set the wrong example. Highly educated mothers also value the learning of their native language, but all of them report speaking frequently Dutch with their children because it seems to be considered better for a successful school career in the Netherlands. The same is true for some of the middle educated mothers.

Interviewer: "In which language do you communicate with X?"

Parent: "I speak a lot of Dutch with my child, sometimes also Moroccan. We live here. The future of our children lies here, they have to make it here. They have to make it in Dutch, therefore they have to learn the language" (Berber, middle educated).

Another mother answers the question mentioned above as followed:

Parent: "During telling or reading stories I speak Dutch with X. This is better. First I had my doubts, but it is also good for his native language. I decided to read stories in Dutch. They have to learn it at home, that's important for school. It becomes very difficult for a child at school when he can't understand things that are spoken in Dutch. In that way, he could easily fall behind" (Berber, middle educated).

\section{Attributions of School Success}

All mothers consider three factors of importance with respect to scholastic achievement: the intelligence of the child, the supportive role of parents, and the degree to which schools provide homework. Four mothers who cannot read and seven less educated mothers attribute school failure to the child.

Interviewer: "And what's according to you the reason for not being succesful at school?"

Parent: "Well, that has to do with the child, he hasn't tried hard enough, so he just doesn't want to learn" (Berber, mother who cannot read).

Five out of seven less educated mothers mention lack of school success in reference to the support of parents or school. Lack of motivation and lack of effort seem to be the most important factors. Some mentioned aspects concerning good manners like listening to the teachers. Mothers report to stress the importance of these manners at home; they also inform teachers about the behavior of their child and monitor whether the child is doing schoolwork at home. Being successful at school seems to be linked to schools that provide pupils with much homework.

Interviewer: "What do you think is the main reason for being succesful in school?"

Parent: "I think the school has to pay more attention, they should give more homework. They shouldn't let them do things just like that. They get very little homework. It's their task to teach children properly and to make them intelligent" (Arab, less educated).

Parent: "If you know it doesn't go well at school, than they (teachers) have to help by giving children lots of homework, or they have to get some extra lessons at school" (Berber, mother who cannot read).

Interviewer: "How do you mean extra lessons?"

Parent: "Well, extra lessons after school-time if there are difficulties." 
Four out of seven mothers with less education seem to link individual school success to the role of parents. These mothers consistently mention a combination of different aspects, while mothers who cannot read tend to associate scholastic achievement with a single aspect: the child in a central position in the learning process.

Interviewer: "What do you think is the main reason for being succesful in school?"

Parent: "Well, it has of course also to do with school. Maybe they don't offer enough or suitable help. But there are children that will not be successful even though you provide them the proper help. Maybe their brains are not capable of processing information" (Arab, less educated).

The attribution of school success of children by mothers who cannot read and less educated mothers seems to be inconsistent. Lack of success is attributed to internal factors: in this case the individual efforts of the child; positive school results seem to be attributed to external factors, in particular the school. Although this seems contradictory, it is in line with the importance that mothers give to school with respect to the cognitive development of their children.

Highly and middle educated mothers appear to attribute, in the case of a child of average intelligence, success or lack of success to the parents and the school. The role of parents in this process appears to be one of providing stimuli through which children can acquire knowledge and scholastic skills. The role of school is expressed in terms of the methods used, and the degree to which teachers maintain the interest of children.

Interviewer: "What do you think is the main reason for being successful in school?"

Parent: "Well it has to do with the child, but also with a secure home environment, that's the basis of it all. At home a child has to get protection, warmth and love. Structure and regularity are also important. These things affect the school achievements of a child. School plays an important role in achieving positive school results. The quality of the teachers also plays an important role. Are they able to adapt to the interests of children? Therefore I think that the quality of the school, the home environment, and the kind of parenting are important. But also the capacity of a child, whether the kind of education suits him or not" (Berber, middle educated).

Parent: "Well, I think both sides are important. The school and the home environment. You see, it's not enough to rely just on what the school offers. The school is helpful. But it's also good to take up the learning subjects at home" (Arab, highly educated).
The Importance of Education and Expectations

The importance that mothers who cannot read and less educated mothers assign to education and the expectations they have do not differ from middle educated and highly educated mothers. The arguments in favor of education can be divided into two aspects. The first one concerns personal development. In this respect, education is seen as enrichment for the individual himself. Education provides knowledge that helps to understand the surrounding world and that shapes life itself. The second aspect concerns independence. All the mothers claim they value this aspect so that their children can make their own decisions, can shape their own lives, and can participate in society. To the question of what mothers think is important about education, a couple of mothers responded as followed:

Parent: "Just to be able to help herself in this society, not being dependent on others. I think that's very important, being independent, doing things on your own" (Arab, mother who cannot read).

Parent: "I think it's important to create opportunities for children to develop their own opinions. It's worth listening to them. I want them to become assertive, to take initiative, to say what they think, to express their opinions, and to express themselves. That's very important for this society, it's important for success, you have to come along with everything. It's also important for school" (Berber, middle educated).

Parent: "I think it's important for children not to obey always. We did that in former times, it was seen as something good. We had to listen to the teacher and to be quiet. These children must not do that. They must become assertive. Education broadens your world, it allows you in a certain way to deal with life. Education civilizes human beings" (Arab, highly educated).

All the mothers report that they value education as a means for their children to get a professional job. The expectations appear to be high with regard to an academic career. Higher education is what the mothers seem to aspire for their children. These expectations are based on the demands of society. The mothers say that getting a diploma is necessary today.

Interviewer: "What do you think is the most important goal for your child to achieve in school?"

Parent: "I hope that he will study well to get a higher educational level in order to acquire a better professional job. I value a higher education level very much" (Berber, mother who cannot read).

Parent: "I hope she will obtain a high education level, HAVO for example. It's no problem to work very hard to obtain that level. I want her to achieve something in 
her life, doing a master study. HBO is also ok with me. I hope something in that direction. But if she is happy with something less, then I'm not going to force her" (Arab, less educated).

Parent: "Well, getting a high educational level. A good level in order to obtain a professional career. Of course I expect a high level, but I must also be realistic" (Berber, middle educated).

Parent: "I think it's of great importance to graduate, to get a diploma. It provides the future much certainty, than without. Live becomes somewhat easier. And it's of course very important for your own development" (Arab, highly educated).

\section{Discussion}

Mothers' Perceptions of Stimulating Children's Cognitive Development

With respect to the socialization of their children, the majority of mothers who cannot read and less educated mothers stressed the social and moral development. The moment at which this development starts appears to be at an earlier age than the cognitive development. The perceptions of the parents in our study correspond with the findings of a study by McGillicuddy-De Lisi and Subramanian (1996). Their study showed differences of opinion between parents from individualistic and collectivistic cultures regarding the ages at which mothers expect the development of physical, cognitive, and social skills to take place. In individualistic Western cultures, for instance, the development of cognitive skills begins at an earlier age (Pomerleau et al. 1991). In collectivistic cultures, on the other hand, stress is put upon the development of social and moral skills (Jose et al. 2000; Rudy and Grusec 2001). These views are also consistent with the results of a study by Okagaki and Sternberg (1993). In this respect we found remarkable indications of differences in development stages between mothers who cannot read, less educated mothers, middle and highly educated mothers. Mothers who cannot read seem to expect certain cognitive skills at an older age. These insights are of specific importance in relation to the expected and required development for entering primary school. A comprehensive study on the moments in time in which mothers expect certain cognitive skills in relation to the demands of the school would be helpful to gain a better understanding of the cognitive expectations of mothers, as it will provide important information for schools.

On the one hand, mothers who cannot read and less educated mothers tend to link cognitive development strictly to maturity. These mothers seem to consider this development as something that happens naturally; it does not require any intervention from the parents. Scholastic skills are considered to develop in a natural way, as children get older. In this perception the cognitive development of children is mainly determined by biological and physiological factors and to a much lesser extent by the social environment. On the other hand, mothers who cannot read and mothers with less education report that cognitive stimulation at an early age is of great importance to learning processes at school. All these mothers recognize the influential role that educated mothers have in the development of their children. These views indicate a certain shift in the traditional collectivistic perceptions. From a dynamic theoretical point of view (Lamb and Sternberg 1992) it is possible that mothers change their views on the basis of their earlier experiences with their older children. These perceptual changes are related to environmental changes. It is also possible that mothers change their perceptions as a result of interactions with teachers, as stated in the transactional model of McGillicuddy-De Lisi and Subramanian (1996).

It is the educational context of the family that especially influences these perceptions. No differences in perceptions appeared between Berber and Arabic mothers who cannot read and who are less educated. These mothers tend in general to focus on the transmission of social and moral skills. On the contrary, middle educated and highly educated mothers seem to stress the development of cognitive skills in their socialization practices and report providing different experiences for their children to enhance cognitive development. In this respect apparently there were no differences between Arabic and Berber mothers. In this regard our study also differs with the findings of Cote and Bornstein (2003) that focus on changes in the cultural perceptions of parents.

In this study we found interesting changes in the perceptions of Moroccan Arabic and Berber mothers who cannot read and mothers who are less educated. These mothers seem to adjust their traditional views in accordance with the demands of the school. These findings put the research conclusions of Hermans (1995), Klatter-Folmer (1997) and Van der Veen (2003) in a different light. Although those studies reported on the perceptions of parents with regard to school success, differences among educational levels of parents were not manifested. The results of our study suggest a strong influence of the educational level on the parental perceptions that would merit a more comprehensive study. The indications of the adjusted traditional perceptions of the mothers (who cannot read and mothers with less education) on the demands of the school indicate an interesting change of perceptions of origin about scholastic learning. It is of great interest to explore the dynamics of these cognitions in relation to 
acculturating mothers. To gain insight to what extent and on which grounds the perceptions of acculturating mothers differ from those mothers of the country of origin and to what extent their perceptions resemble those of the mothers of the country to which they immigrated. It's also of great importance in this context to explore to what extent the educational level of the mother influences the changing cognitions of acculturating mothers and how their perceptions relate both to the new home environment and to their country of origin.

\section{Mothers' Stimulating Activities for Cognitive Development}

With respect to stimulating practices for cognitive development, marked differences appeared between mothers who cannot read and less educated mothers on one side and middle educated and highly educated mothers on the other. Most of the activities that were reported by mothers who cannot read and mothers with less education are in connection with conversations with the child and visits of family members. Those visits are considered to be important for acquiring social skills and for learning the Moroccan language. Furthermore, children are allowed to listen to music of the native country of their parents and to watch television programs in their native language.

Mothers who cannot read and mothers with less education emphasized that it is important for their children to maintain their cultural and religious identity. These matters take priority over the development of cognitive skills. The mothers recognize that they have an important responsibility in the social and religious development of their children, especially because this process should start at an early age, while the stimulation of cognitive abilities can wait. These perceptions of the parents in our study are in accordance with the findings on the cognitions of immigrant parents (Delgado and Ford 1998; Klatter-Folmer 1997; Van der Veen 2003). Once again, they reflect the strong motivation to maintain their cultural identity. The study of Klatter-Folmer (1997) indicated a negative influence of traditional institutions on the stimulating practices of parents. Continued research would be useful to explore to what extent this finding applies to a large group Berber and Arabic mothers in the Netherlands.

Although mothers who cannot read and less educated mothers tend to profess disbelief that young children are able to do cognitive exercises at an early age, they reportedly are fully aware of the great importance of encouraging scholastic skills. These perceptions represent a belief in the influence that parents ascribe to themselves in the cognitive development of their children. Interestingly, about half of the mothers who cannot read and less educated mothers report that they would like to encourage this development but that they are not able to do so because of their illiteracy. The most frequently mentioned activities undertaken include listening to, watching and participating in interactions. The way mothers who cannot read encourage their children to acquire knowledge is characterized as observational and that is coherent with the findings of McGillicuddy-De Lisi and Subramanian (1996). Mothers who cannot read and mothers with less education tend to frame a cognitive socialization context where learning activities take observational forms. These mothers would benefit from education and training programs to expand their knowledge about developmental stages of children and with which activities and toys mothers could contribute to their children's cognitive development.

Interestingly, all mothers who cannot read and less educated mothers pointed out that they do not believe that children can acquire knowledge by playing. Middle educated and highly educated mothers, however, seem to see playing as a pre-requisite for learning. Mothers who cannot read and mothers with less education reported viewing playing as amusement. This finding is in line with the research of Palacios et al. (1992). Although playing nowadays is considered of importance for early development of cognitive skills, mothers who cannot read and less educated mothers are not taking any initiative in this respect. One cannot really blame them for that because, in their perception, Dutch primary schools are not strongly involved with cognitive activities in the first two grades (with four and 5 year olds). In 1985, however, the goal of the fusion of schools for early childhood and schools for primary education was exactly that: to strive for the educational development of children in which playing and learning are no longer directly linked to the specific age of the child. In this respect, there is more work to be done.

\section{Limitations}

The findings of this study need to be viewed in the light of the following limitations. First, the present study explored mothers' perceptions and their stimulating activities to foster children's cognitive development. No observations were made to check the actual implications of their beliefs. It's also possible that some alternative stimulating activities remained unexposed. Secondly, the present study focused solely on mothers' beliefs from the point of view as the main caregiver. Further research needs to explore fathers' perceptions on children's cognitive development and activities they undertake to encourage the aimed development in order to gain a better comprehension of Moroccan parental beliefs on children's cognitive development and to what extent fathers contribute to this. Thirdly, this study did not address possible socialization differences between girls and boys. No insight is gained into whether mothers have 
different perceptions or expectations of boys and girls and whether they undertake different stimulating activities accordingly. Some perceptions may be influenced by gender differences (Arnet 1995). Further research on this topic is desirable. In the fourth place, this study failed to associate the different educational backgrounds of Moroccan mothers and their different perceptions and stimulating activities with the current academic achievement of their children. Differences between high and low achieving children may be related to other contexts than differences in perceptions and practices. Differences in terms of characteristics of schools, teachers' attitude, school climate, influence of peer groups also influence academic achievement (Gutman and McLoyd 2000). Further research needs to be done to gain insight into what extent and in which way different perceptions of Moroccan mothers and different stimulating activities influence their children's cognitive development. However, the present study provides important information on the Moroccan mothers' beliefs and the activities they undertake to foster cognitive development. The ethnic background of the parents, whether Arabic or Berber, did not make a difference in this respect. Educational background, however, did make a difference. Mothers who cannot read and mothers with less education ascribe an important role to teachers in preparing children for formal learning and acknowledge the importance of academic abilities before entering the primary school. They would like to provide their children learning experiences to facilitate the learning process at school, but report they cannot because they lack the necessary abilities.

Open Access This article is distributed under the terms of the Creative Commons Attribution Noncommercial License which permits any noncommercial use, distribution, and reproduction in any medium, provided the original author(s) and source are credited.

\section{References}

Arnet, J. (1995). Broad and narrow socialization: The family in the context of a cultural theory. Journal of Marriage and the Family, 57, 617-628.

Bempechat, J., Graham, S. E., \& Jimenez, N. V. (1999). The socialization of achievement in poor and minority students: A comparative study. Journal of Cross-Cultural Psychology, 30, 139-158.

Blackledge, D., \& Hunt, B. (1985). Sociological interpretations of education. London: Croom helm.

Bornstein, M. H., \& Cote, L. (2004). Mothers' parenting cognitions in cultures of origin, acculturating cultures and cultures of destination. Child Development, 75, 221-235.

Bornstein, M. H., Tal, J., \& Tamis-LeMonda, C. S. (1991). Parenting in cross-cultural perspective: The United States, France, and Japan. In M. H. Bornstein (Ed.), Cultural approaches to parenting (pp. 69-90). Hillsdale, NJ: Erlbaum.

Bradley, R. H., \& Corwyn, R. F. (2002). Socio-economic status and child development. Annual Review of Psychology, 53, 371-399.
Central Bureau of Statistics. (2009). Kerncijfers. Den Haag: CBS Statline.

Chafik, M. (2004). Imazighen. De Berbers en hun geschiedenis. Amsterdam: Bullaaq.

Cote, L., \& Bornstein, M. H. (2003). Cultural and parenting cognitions in acculturating cultures: Cultural comparisons and developmental continuity and stability (1). Journal of CrossCultural Psychology, 34, 323-349.

De Jong, P. F., \& Leseman, P. P. M. (2001). Lasting effects of home literacy on reading achievement in school. Journal of School Psychology, 39, 389-414.

Decoviç, M., \& Gerris, J. (1992). Parental reasoning, social class, and child-rearing behaviors. Journal of Marriage and the Family, 3, 675-685.

Delgado, B. M., \& Ford, L. (1998). Parental perceptions of child development among low-income Mexican American families. Journal of Child and Family Studies, 7, 469-481.

Dockrell, J., Stuart, M., \& King, D. (2004). Supporting early oral language. Literacy Today, 40, 16-17.

Englund, M. M., Luckner, A. M. E., Whaley, G. J. L., \& Egeland, B. (2004). Children's achievement in early elementary school: Longitudinal effects of parental involvement, expectations, and quality of assistance. Journal of Educational Psychology, 96, 723-730.

Gauvain, M. (1998). Cognitive development in social and cultural context. Current Directions in Psychological Science, 7, 188-192.

Goodnow, J. J. (1998). Parents' ideas, actions, and feelings: Models and methods from developmental and social psychology. Child Development, 59, 286-320.

Gottfried, A. E., Fleming, J. S., \& Gottfried, A. W. (1998). The role of a cognitively stimulating home environment in children's academic intrinsic motivation: A longitudinal study. Child Development, 69, 1448-1460.

Greenfield, P. M., Keller, H., Fuligni, A., \& Maynard, A. (2003). Cultural pathways through universal development. Annual Review of Psychology, 54, 461-490.

Guo, G., \& Harris, K. M. (2000). The mechanisms mediating the effects of poverty on children's intellectual development. Demography, 37, 431-447.

Gutman, L. M., \& McLoyd, V. C. (2000). Parents' management of their children's education within the home, at school, and in the community: An examination of African American families living in poverty. Urban Review, 32, 1-24.

Hart, B., \& Risley, T. R. (2003). The early catastrophe: The 30 million word gap by age 3. American Educator, 27, 4-9.

Hatano, G., \& Wertsch, J. V. (2001). Sociocultural approaches to cognitive development: The constitutions of culture in mind. Human Development, 44, 77-83.

Hauser, R. M. (1994). Measuring socioeconomic status in studies of child development. Child Development, 65, 1541-1545.

Hermans, P. (1995). Moroccan immigrants and school success. International Journal of Education Research, 23, 33-43.

Jose, P. E., Huntsinger, C. S., Huntsinger, P. R., \& Liaw, F. R. (2000). Parental values and practices relevant to young children's social development in Taiwan and the United States. Journal of CrossCultural Psychology, 31, 677-702.

Klatter-Folmer, J. (1997). Schoolsucces van Turkse kinderen in relatie tot hun sociaal-culturele oriëntatie. Migrantenstudies, 13, $25-41$.

Lamb, M. E., \& Sternberg, K. J. (1992). Sociocultural perspectives on parental care. In M. E. Lamb, K. J. Sternberg, C. P. Hwang, \& A. G. Broberg (Eds.), Child care in context. Cross-cultural perspectives (pp. 1-26). Hillsdale, NJ: Erlbaum.

Landry, S. H., Smith, K. E., \& Swank, P. R. (2003). The importance of parenting during early childhood for school-age development. Developmental Neuropsychology, 24, 559-591. 
Landry, S. H., Smith, K. E., Swank, P. R., \& Miller-Loncar, C. L. (2000). Early maternal and child influences on children's later independent cognitive and social functioning. Child Development, 71, 358-375.

Leseman, P. P. M. (1990). Structurele en pedagogische determinanten van schoolloopbanen. Rotterdam: Project Onderwijs en Sociaal Milieu.

Leseman, P. P. M. (2002). Early childhood education and care for children from low-income or minority backgrounds. Paris: OECD.

Leseman, P. P. M., Sysling, F. F., Jap-A-Joe, S. R., \& Sahin, S. (1995). Gezinsdeterminanten van de cognitieve ontwikkeling van vierjarige Nederlandse, Surinaamse en Turkse kleuters. Pedagogische Studiën, 72, 186-205.

LeVine, R. A., Miller, P. M., Richman, A. L., \& LeVine, S. (1996). Education and mother-infant interaction: A Mexican case study. In S. Harkness \& C. M. Super (Eds.), Culture and human development. Parents' cultural belief systems: Their origins, expressions, and consequences (pp. 254-269). New York: Guilford.

McGillicuddy-De Lisi, A. V., \& Subramanian, S. (1996). How do children develop knowledge? Beliefs of Tanzanian and American mothers. In S. Harkness \& C. M. Super (Eds.), Culture and human development. Parents' cultural belief systems: Their origins, expressions, and consequences (pp. 143-168). New York: Guilford.

Menaghan, E. G., \& Parcel, T. L. (1991). Determining children's home environments: The impact of maternal characteristics and current occupational and family conditions. Journal of Marriage and the Family, 53, 417-431.

OECD. (2005). School factors related to quality and equity. Paris: OECD.

Ogbu, J. U. (1978). Minority education and caste. The American system in cross-cultural perspecitve. New York: Academic Press.

Okagaki, L., \& French, P. A. (1995). Encouraging school achievement in Mexican American Children. Hispanic Journal of Behavioral Sciences, 17, 160-180.

Okagaki, L., \& French, P. A. (1998). Parenting and children's school achievement: A multi-ethnic perspective. American Educational Research Journal, 35, 123-144.

Okagaki, L., \& Sternberg, R. J. (1993). Parental beliefs and children's school performance. Child Development, 64, 36-56.

Palacios, J., Gonzalez, M. M., \& Moren, M. C. (1992). Stimulating the child in the zone of proximal development: The role of parents' ideas. In I. E. Sigel, A. V. McGillicuddy-De Lisi, \& J. J. Goodnow (Eds.), Parental belief system: The psychological consequences for children (Vol. 2, pp. 71-94). Hillsdale, NJ: Erlbaum.

Parks, P. L., \& Smeriglio, V. L. (1986). Relationships among parenting knowledge, quality of stimulation in the home and infant development. Family Relations, 35, 411-416.

Pels, T. (2000). Muslim families from Marocco in the Netherlands. Gender dynamics and fathers'roles in a context of change. Current Sociology, 48, 75-93.

Petrill, S. A., Pike, A., Price, T., \& Plomin, R. (2004). Chaos in the home and socioeconomic status are associated with cognitive development in early childhood: Environmental mediators identified in a genetic design. Intelligence, 32, 445-460.

Pomerleau, A., Malcuit, G., \& Sabatier, C. (1991). Child rearing practices and parental beliefs in three cultural groups of Montréal: Québécois, Vietnamese, Haitian. In M. H. Bornstein (Ed.), Cultural approaches to parenting (pp. 45-68). Hillsdale, NJ: Erlbaum.

Raviv, T., Kessenich, M., \& Morrison, F. J. (2004). A mediational model of the association between socio-economic status and three-year-old language abilities: The role of parenting factors. Early Childhood Research Quarterly, 19, 528-547.

Rudy, D., \& Grusec, J. E. (2001). Correlates of authoritarian parenting in individualist and collectivist cultures and implications for understanding the transmission of values. Journal of Cross-Cultural Psychology, 32, 202-212.

Sigel, I. E., \& Kim, M.-I. (1996). The answer depends on the question: A conceptual and methodological analysis of a parent belief-behavior interview regarding children's learning. In S. Harkness \& C. M. Super (Eds.), Culture and human development. Parents' cultural belief systems: Their origins, expressions, and consequences (pp. 83-120). New York: Guilford.

Steinberg, L., Lamborn, S. D., Dornbusch, S. M., \& Darling, N. (1992). Impact of parenting practices on adolescent achievement: Authoritative parenting, school involvement and encouragement to succeed. Child Development, 63, 1266-1281.

Strauss, A. L., \& Corbin, J. (1990). Basics of qualitative research. Grounded theory procedures and techniques. London: Sage.

Van der Veen, I. (2003). Parents' education and their encouragement of successful secondary school students from ethnic minorities in the Netherlands. Social Psychology of Education, 6, 233-250.

Vygotsky, L. S. (1978). Mind in society: The development of higher psychological processes. Cambridge, MA: Harvard University Press.

Walker, D., Greenwood, C., Hart, B., \& Carta, J. (1994). Prediction of school outcome based on early language production and socioeconomic factors. Child Development, 65, 606-621. 